American Journal of Qualitative Research

June 2021, Vol. 5 No. 1, pp. 206-221

https://doi.org/10.29333/ajqr/10930

(C) 2021 AJQR. http://www.ajqr.org
AMERIGAN

JOURNAL OF QUALTATIUE

RESEARCH

ISSN: $2576-2141$

\title{
The Invisible Influences Behind Joint Interviews: An Examination of Relational Expectations and Technology Use
}

\author{
Jamie Foster Campbell ${ }^{1}$ \\ University of Illinois at Chicago, USA
}

\begin{abstract}
This paper presents a reflexive account of how the use of joint interviews with romantic dyads creates a unique conversational space for people to reflect on relational practices that are often invisible. The contribution this paper seeks to offer is to encourage other qualitative scholars to think critically about the use of joint interviews as a data collection method when studying mediated communication and technology's place in relational life. Using the data from a larger research project, I argue that with joint interviews, the process of metacommunication inevitably impacts the couple's behaviors and direct communication at that moment, and potentially after the interview ends. Therefore, it is important for future scholars using joint interviews to include a follow-up interview with the couple to learn more about how their relational communication, especially over mediated channels, transforms after the interview concludes. Questions about the effect of joint interviews as a research practice are presented.
\end{abstract}

KEYWORDS: Communication Rules, Expectancy Violation Theory, Joint Interviews, Mobile Communication, Romantic Relationships.

Qualitative research as a method allows social scientists to weave their participants' voices with their own to make sense of certain phenomena. The choice of each research practice scholars use is based on the questions they ask and depends on the context available to explore these inquiries (Denzin \& Lincoln, 2018). Every time social scientists design a qualitative project, they are reminded that their work is situated within relationships; the relationship between the literature, the unfolding process of their research design, and the individuals they study (Baym, 2008). Under the umbrella of qualitative methods, there are many different research practices to choose from as a way to collect data (e.g., observations, interviews, reviewing texts, ethnography, etc.). For this paper, and the larger conversation that follows, I will focus on interviews; the primary method I used to investigate how the widespread adoption of mobile technology makes us reexamine what it means to live in a relational world.

Interviews allow us to ask people about their perceptions and how they experience, define, and think about all aspects of society. The data obtained from an interview is based on someone's perception rooted in time and space (i.e., where they are situated in their life, their relationships, and the social world when asked questions; Allan, 1980). When conducting qualitative interviews, the research becomes about the participants; their stories, their beliefs, and their view of life (Lindlof \& Taylor, 2002). Social scientists that utilize interviews understand that this method

\footnotetext{
${ }^{1}$ Correspondent Author E-Mail: jfoste2@uic.edu
} 
choice prompts discussion about relational topics and the communication practices people may not normally think about outside of this setting. In other words, individuals may not be aware of their communication habits or mediated practices until they are directly asked to reflect on them.

The purpose of this paper is to present a reflexive account of how the use of joint interviews with a romantic dyad produces a unique conversational space for unspoken practices to be discovered. This research is based on a larger study that sought to investigate the development of communication rules surrounding technology use. The findings from this investigation revealed that all couples identified rules that evolve through direct communication and observations of each other's personal communication styles. For example, I discovered several instances in which couples unanimously agree that they've had an explicit conversation surrounding their expectations for technology use and digital communication with one another. It appears that this explicit dialogue helps maintain the day-to-day relationship but is also never finished. Second, there were many instances throughout these interviews where couples discussed the progression of their communication practices and media use that evolved naturally over time. Couples begin to form implicit expectations after an action is repeatedly performed in a certain way, although these are not directly spoken about before the interview setting. These implicit rules are the behind the scenes expectations that frame a couple's interactions.

While I analyzed the data for this research study, I began to question if the implicit rules brought up by my informants become explicit due to the interview context. In other words, did the occurrence of joint interviews transform how the couple makes sense of their shared expectations for media use in a direct way that altered their behavior once our interaction ended? The choice to conduct joint interviews with romantic partners may present an opportunity for the couple to find themselves talking about the way technology is embedded into their partnership to a third party, even if they've never directly had these conversations before the research context. The contribution this paper seeks to offer is to encourage other qualitative scholars to think critically about the use of joint interviews as a research method when studying relational communication. Several previous scholars have addressed the advantages and disadvantages of joint interviews (see Allan, 1980; Bjørnholt \& Farstad, 2014; Eisikovits \& Koren, 2010; Mavhandu-Mudzusi, 2018; Morgan, 2016; Polak \& Green, 2016; Taylor \& de Vocht, 2011; Zarhin, 2018); however, I believe the idea of metacommunication around technology use is another affordance of joint interviews that extends beyond previous work which examines mediated practices of communication. Before I continue discussing the implications of joint interviews, I will first provide some additional background on the larger research study framing this paper for context.

\section{Background: Summary of the Original Study}

The goal of this research project was to further understand how mediated communication is reshaping romantic partners' interactions. Specifically, I examined how couples negotiate communication rules surrounding their media use and how these expectations shift throughout the couple's courtship over time. Shimanoff (1980) defined rules as "a followable prescription that indicates what behavior is obligated, preferred, and prohibited in certain contexts" (p. 57). Twenty years later, Baxter et al. (2001) similarly explain that a rule is a commonly shared understanding of appropriate behavior. These interactional rules help coordinate social meaning and are based on a shared belief (Roggensack \& Sillars, 2014). According to Shimanoff, couples develop unique rules that are consciously and unconsciously followed; these rules may also be referred to as expectations or normative behavior.

What first intrigued me about the study of interpersonal relationships and mediated communication was the idea that our connections create the fabric of our social world. The drive 
to explore this topic was born out of this interest and expanded based on my observations of technology's role in our contemporary experience. I move through the world both as an academic and as an individual who is constantly navigating my interpersonal connections. I rely on communication technologies to develop and maintain my geographically close and long-distance relationships. This experience of watching myself, and those around me, negotiate the layers of relational communication through a mediated world is what ultimately led to my choice to conduct this research; which further examines the relational structures that naturally unfold in a romantic partnership.

This research study guiding my larger discussion of the use of joint interviews as a data collection tool is framed by expectancy violation theory (EVT). EVT claims that expectations are informed by social norms and idiosyncrasies (Burgoon \& Jones, 1976). Social norms are general expectations individuals from the same culture share, while idiosyncratic norms are expectations that are unique to the relational pair (Hall et al., 2014). Past EVT research discovered that social expectations guide our relational behavior and have repeated effects on how we judge our relational partner's actions (Burgoon, 2015). Therefore, under this framework, if expectations are violated (which is perceived as a negative act by the relational couple), it can result in an unfavorable evaluation of the person who broke the rule. Contemporary uses of EVT correlate with Shimanoff's (1980) explanation of how interpersonal dyads use communication rules to regulate their interactions. These 'rules' or expectations are then conceptualized as expected behavior based on the interactional context (i.e., the setting), relationship type (e.g., the degree of closeness between the dyad), and an individual's unique characteristics (e.g., gender identity, age, communication style, past experiences, etc.). Ultimately, this theoretical framework allows for expectations, violations, and responses to the violations to be visible, while considering how communication rules are co-constructed and negotiated throughout a couple's courtship. With this in mind, the following research questions were put forward:

RQ1: How do couples co-produce expectations for mobile communication?

RQ2: How do couples negotiate their communication rules during an expectation violation?

To answer the research questions guiding this original study, semi-structured interviews were conducted with 18 monogamous couples $(N=36)$. Interviews took approximately 30-to-60 minutes, were audio-recorded, and conducted in-person $(n=15)$, over the phone $(n=1)$, or online through Skype $(n=2)$ based on what was most convenient for the participants. The sample consisted of people who were 19-42 years old, with an average age of 31 years old. Couples selfidentified as straight $(n=16)$ or gay $(n=2)$, and they met their partner through mutual friends, at work/school, or online. For this sample, the relationship length varied from six months to 22 years, with an average length of 6.14 years. Finally, participants reported their relationships status as married $(n=7)$, engaged $(n=3)$, living together $(n=4)$, and dating $(n=4)$.

Participants were recruited for interviews in three ways. First, a recruitment message was posted to a public Facebook page created for this research study. Second, a flyer was posted on public announcement boards at a large Midwestern university to reach a wider audience that may not be online. Last, snowball sampling was used to encourage participants to tell other eligible couples about this study. This recruitment continued until I reached saturation and had enough data for a rich analysis. Saturation occurs where there is no new information obtained during the data collection and data analysis process (Mavhandu-Mudzusi, 2018; Morse, 1995). Although data saturation was reached after the 16th couple, two more dyads were interviewed to ensure data comprehensiveness (a procedure similar to Mavhandu-Mudzusi, 2018). Interviews concluded after 
the 18th couple when thematic saturation was met (Guest et al., 2020) and the number of interviews conducted was sufficient for accomplishing the research objectives (Morse, 1995).

Through the use of joint interviews, I was able to compare individual experiences, perceptions, and narratives about the couple's mobile communication (a procedure similar to Mavhandu-Mudzusi, 2018). Interviewing couples together also provided the opportunity to analyze the dyad's experiences and technology preferences more directly (Scissors \& Gergle, 2013), while uncovering when their accounts differed from one another. Finally, the use of semi-structured joint interviews as a primary method for this study allowed me to discover information about my research questions. Yet it was flexible enough so I could get a better sense of how technology is layered into each couple's unique communication patterns (Brinkmann, 2018; Lindlof \& Taylor, 2002).

To answer my first research question, I concluded that some of the rules are explicitly constructed, others are implicitly made, and some are both - they are woven together and become layered into a couple's relational communication throughout their courtship. What may start as an implicit rule becomes an explicit expectation over time because there is a need for couples to change their communication practices, which then creates an occasion for specific relational talk.

For my second research question, results revealed that dyads develop communication rules to successfully navigate their multiple channels of communication. Similar to findings in previous research, most communication rules emerged out of an earlier conflict or unwanted digital behavior (Baxter et al., 2001; Shimanoff, 1980). Many of the couples interviewed explained that one way to mitigate these tensions was to create a formal expectation for future interactions. However, what this research adds to the conversation is that communication rules are flexible.

So, the main theme to emerge in response to this second research question is that rules are contextual. Throughout the joint interviews, couples discussed how there were times when their pre-established rules changed due to situational needs (e.g., during travel, a change in their daily schedule, the need to spend quality time together without the distraction of mobile phones, and so on). Overall, what this study contributes to the scholarship is that communication rules come and go as the individuals in the relationship transform their unique communication practices and move through different relational milestones. In the end, this exploratory investigation found that the practice of creating implicit and explicit rules exists as part of a natural negotiation process in romantic relationships. Furthermore, it shows that the negotiation of technology (at an individual and dyadic level) is often a dynamic and complex process. Rules are not rigid; they are fluid and develop naturally over time just like our relationships.

As I contemplated the central findings of this study, I began to reflect on the use of semistructured joint interviews as a research practice: how does this research process impact relational expectations surrounding technology use? Furthermore, how does the action of asking couples to tell stories and discuss their perception of their technology habits alter the implicit communication rules that are discussed after the interview concludes? So, for the remainder of this paper, I seek to unpack how joint interviews, as a method of data collection, influence relational communication and the discussion of expectations surrounding technology use.

\section{Joint Interviews: A Qualitative Research Practice}

There are three key points to my argument that contribute to the literature on using joint interviews as a research method. First, the act of dyadic communication in the presence of the researcher may influence the evolution of implicit rules becoming explicit. I believe this is a direct result of the process of asking couples to openly discuss and reflect on their behaviors and preferences in the company of their significant other. Second, intra-couple conversations address 
unspoken topics about relational communication in the context of the interview. In other words, an advantage of joint interviews is that they provide a space for people to reflect on communication habits that are often invisible. Third, future scholars using joint interviews as a research practice can benefit from conducting a follow-up interview with the couple to learn more about how their relational communication, especially over mediated channels, transforms after the interview concludes. Of course, follow-up interviews may not always be possible for a variety of reasons, which is important for scholars to consider as they design their research study. For example, it may be difficult to get both members of the couple to participate in a second interview. Many of the same challenges present in longitudinal research may also be experienced by the qualitative researcher seeking to perform follow-up interviews (see Hermanowicz, 2013; Neale, 2018; Sanip, 2020). Nonetheless, it is something to consider as a way to understand how the process of joint interviews impacts the couple in the future. Next, I will offer a clear definition of joint interviews as informed by previous research to help lay the foundation of this data collection tool.

The phrase joint interview describes the process of doing a qualitative interview with two people at one time. In contrast to dyadic interviews, which consider the couple as the unit of analysis, joint interviews view the individuals as the unit of analysis. More specifically, a joint interview is an encounter between an interviewer and a dyad that interacts and responds to questions together (Mavhandu-Mudzusi, 2018). Polak and Green (2016) further explain:

\section{Joint interviews often mean interviews with two people who have a prior relationship, interviewed at the same time. Here, the aim of using joint interviews is to study two people rather than the couple, the focus of analysis is then not so much on interactions but on the two perspectives elicited from the one interview. (pp. 1639-1640)}

In this sense, each individual's narrative in response to the interviewer's questions is what produces the initial data. Although, I argue that the ability to view the couple's nonverbal interactions while discussing a relational topic also becomes part of the data (Morgan, 2016). It is important to realize this can only be accomplished when conducting interviews in-person or through a video chat application (like Zoom or Skype). As noted above one couple from this study was interviewed over the phone due to geographic and technical constraints. I believe phone-based interviews are still a valuable means for gaining insight into a couple's relational communication practices and technology use, albeit the researcher does sacrifice obtaining rich nonverbal observations beyond paralinguistic cues received through a telephone conversation.

Overall, joint interviews produce a different kind of data, one that cultivates stories of "weness," which can ultimately help researchers better understand the couple's perspective (Torgé, 2013). The quality of data received from a joint interview is based on the nature of the interaction between the dyad, which can be a strength and limitation of this research design choice (MavhanduMudzusi, 2018; Morgan, 2016). For instance, interviewing couples together can allow the researcher to analyze the dyad's shared experiences and technology habits more candidly (Scissors \& Gergle, 2013), while also uncovering when their accounts diverge from one another. As a research design, I believe joint interviews provide a better opportunity to mirror the experience of how a couple's relationship takes shape in a mediated environment. Similarly, one of the key advantages of joint interviews is that this method choice enables social scientists to witness the interactions of the couple unfold, in real-time, during the interview (Allan, 1980; Jenner \& Myers, 2019; Polak \& Green, 2016).

Another strength of joint interviews is that they provide insight into each couple's unique relational culture (Allan, 1980). The narrative form of a joint interview allows the researcher to see 
communication in action; in a sense, a more complete picture of the relationship can emerge with this data collection choice (Allan, 1980; Bjørnholt \& Farstad, 2014). This can be both an advantage and limitation of joint interviews because what is revealed by the pair together is not something you can get from single interviews alone. However, the presence of a participant's significant other could keep them from sharing information they would normally disclose if their partner was not present (Allan, 1980; Mellor et al., 2013).

Furthermore, joint interviews allow respondents to present themselves as a couple, while also maintaining their individual perspectives on the content in question (Taylor \& de Vocht, 2011). A joint interview, as a data collection tool, can help create a shared picture of the couple that allows the researcher to "learn about each individual's role in the relationship" (Eisikovits \& Koren, 2010, p. 1643). Additionally, memories can be shared and respondents can probe each other's perspectives, thus creating a more conversational style of an interview (Mellor et al., 2013; Polak $\&$ Green, 2016). In sum, the use of joint interviews provides a collaborative approach and can help eliminate elements of interpersonal communication and behavior that may be invisible in individual interviews alone. Next, using the exploratory study framing this paper, I will discuss how this relational dialogue in front of the researcher (i.e., a third party other) influences the process of joint interviews as a methodological practice.

\section{Couple Dynamics and Data Construction: Implicit Rules Become Explicit}

Since the objective of this larger research project is to uncover how couples negotiate their expectations for technology use, I asked my informants about what expectations they have for using technology when they are around each other. As well as what rules they may have for communicating with each other through mediated channels. At first, the majority of participants struggled with these questions (e.g., have you discussed your expectations around digital communication use with one another?). For instance, some initial responses were "I don't know" or "No, I don't think so," while other couples disagreed on their answer to this type of question. For example, Connor, who at the time of the interview was married for five years, quickly said, "Yeah, I'd say so," while his wife Brooke replied laughing, "I was going to say no, not really." Similarly, Jackson and Kayla, who at the time of the interview had been romantically involved for 22 years and were currently married, both agreed that they've never had an explicit discussion about their expectations for technology use. Jackson said "No, we've never had a formal discussion about expectations," he looks at his wife and asks "right?" Then, Kayla responds "Yeah, no rules. We're very transparent with each other when it comes to cell phone use. No rules of engagement have ever needed to be set." Since it takes communication to uncover rules (i.e., relational expectations) it is not surprising that the majority of participants found it hard to identify potential rules they have for digital communication in their relationship. We often don't reflect on or notice these behaviors in our relationship until one is violated since breaking a rule draws attention to the fact that you've had a previously held expectation (Shimanoff, 1980). Furthermore, rules and expectations aren't often explicitly discussed between the couple; these things naturally evolve unless there is a disagreement, which then creates a space for an explicit conversation to emerge.

Many of the implicit rules (or expectations) we have for mediated interactions in close partnerships originate from our own media ideologies we carry with us into each relational interaction. Gershon (2010) explains that media ideologies are how people "understand what one should use a particular medium to accomplish, and how they think the medium affects the message" (p. 53). In a sense, these media ideologies "shape the way [individuals] think about and use different media" (Gershon, 2010, p. 53). They become part of our script for how to communicate with our close relational others in a mediated environment; they embody our set of beliefs about 
mediated communication (Gershon, 2010). Gershon writes "what people think about the media they use will shape the way they use media" (p. 3). That is to say that technology influences the way we think, live, and act in our close partnerships which stem from the ideologies we hold prior to the relationship and how they evolve as well. This was the case for Jackson and Kayla. As I displayed above, their initial reaction to my question about what rules they have surrounding technology use created a response that indicated they do not need or have 'rules' in their relationship. However, as they started to discuss the way they use technology (e.g., sending text messages or their use of social media) it became clear that first, yes, they do have rules for these mediated practices, although most of them are implicit. Second, many of these expectations (e.g., to not overshare hyper-personal details on social media related to their kids or romantic courtship) originated from their own media ideologies for technology's presence in their lives. Therefore, they did not recall having to sit down and have a direct conversation about what is acceptable to post online since the couple appears to share the same beliefs about these practices.

As discussed earlier, the practice of a joint interview presents a fruitful method for investigating dyadic relationships and observing the interaction of the couple unfold as they create their accounts during the interview. While some couples think they do not have any rules or expectations for performing their relationship in a mediated space, in many instances these rules are simply dormant until the couple is directly asked about them. Through this practice, it becomes clear that joint interviews create a space for a previously held implicit rule to evolve into an explicit rule when the pair is asked to discuss relational topics directly from a third party. For example, Charlotte and Brian's conversation during the interview ended with an agreed-upon rule for boundaries around topics that are acceptable (or not) to discuss digitally. Charlotte said:

I guess I expect that we won't have certain conversations about certain topics via text message, I mean we haven't been in an argument or anything but maybe ((laughs)) well now's a good time to say let's not have our first argument occur over text, ya know.

Brian responded with "I agree with that" as he looked at Charlotte. Then, Charlotte continued to explain:

Yeah, that warrants an over the phone or face-to-face conversation. I think I have a certain assumption without having discussed them or experienced them, I have an expectation that a serious topic is not...we should not text about that we should probably have a different mode to address those types of things.

Brian replied while laughing, "Right. New rule I guess." Here we see Charlotte and Brain, who, at the time of this interview were monogamously dating for six months, create an explicit rule about the types of conversations deemed appropriate for a text-based message compared to an inperson or voice-based interaction.

During the interview, this couple explained that they have not experienced a major argument in their relationship yet. However, as their conversation unfolded an explicit rule for future conflict-based interactions appeared. First, Charlotte uses the context of the joint interview to directly discuss her expectations with her boyfriend. The benefit of this co-construction of knowledge provides the researcher with an opportunity to observe the practice of informationgathering; where people get information from their partner and how this informs their everyday 
actions and talk, which ultimately, provides insight into how the relationship operates (Bjørnholt \& Farstad, 2014; Morgan, 2016; Polak \& Green, 2016).

Similarly, Katherine and Justin, who were monogamously dating for 7 months, also presented an example of a rule negotiation during their joint interview. Here is a second instance of an implicit rule becoming explicit during the context of the interview itself. Justin stated, "we don't have any expectations for texting, or ya know basically if I get a text at work and I'm in a meeting or in the middle of something, it's not expected that I will reply right away." Katherine remarks "I mean I expect that you will respond in a reasonable amount of time or I'd worry... like it would be odd if I texted ya today and I didn't hear from you 24 hours later." "Yeah, like a full day," replied Justin. Then Katherine states "Yeah, that would be weird unless you were away or something." Justin responds "I think that's a fair expectation like if I text you and you didn't reply in a day or something I would be like, what's going on?"

In this example, Justin and Katherine, in real-time negotiate the parameters for their previously held implicit expectation about response time. What is interesting about this exchange is that a common, implicit rule that many close partners establish (i.e., responding to a text message in a 'reasonable' amount of time), is framed by previous knowledge about the other person's schedule. The definition of "reasonable amount of time" is highly contextual based on the relationship type; although, Humphreys (2018) points out that knowing the everyday routines of others can be a sign of intimacy in dyadic relationships. Then, when this intimate knowledge is applied to our implicit expectations for digital communication it may also reflect an underlying dependency on connectivity that is now part of a hidden narrative surrounding the maintenance of contemporary romance. Justin and Katherine's dialogue above offers a second instance in which implicit rules may become explicit during the conversation provoked by the interview context. Each participant notes that this is a shared expectation, although they report never directly discussing it before, and now due to the joint interview, the couple negotiates parameters around the rule, thus moving it into an explicit guideline.

\section{Intra-Couple Conversations}

This work extends Bjørnholt and Farstad's (2014) research to demonstrate how joint interviews can illuminate issues that the couple did not previously discuss before the interview context, which the authors argue can add to an unhindered view of relational dynamics. Similarly, I observed these intra-couple conversations as illustrated below with Phoebe and Andrew's (dating and cohabitating for five years) discussion directed towards one another after I asked, "have you ever discussed your expectations surrounding your digital communication with one another?"

Andrew initially responds, "Hmmm, I don't know" and then he looks at his girlfriend. Phoebe states, "what about sometimes if we are sitting on the couch and I am on my phone, you're like 'heeeyyyy' but that's not really... Have you noticed that?" Andrew answers Phoebe's question, he says "Yeah, but we've never discussed it." "Right," says Phoebe, "yeah, we've never discussed it." Andrew jumps in and says, "But, I guess we sort of are now." While Phoebe responds laughing "True." Andrew continues to explain "but I think overall we're pretty good with that stuff. Like if it's something we are doing together; we've never had a problem with getting lost in our phones."

Phoebe turns back to make eye contact with the interviewer and states, "Yeah, usually not. But I guess it's kind of like an expectation we have since our schedules are so different because of the nature of Andrew's job." Andrew replies "Right, so we expect we will both check each other if we are mindlessly on our phone when we're home together." Phoebe says, "And it kind of helps us check back into the moment versus like being checked out on our phones." "Yeah," says 
Andrew, "so I guess it's kind of like a rule, like don't be on your phone while we are spending time together." "Right," says Phoebe, "even if it's just watching TV."

In the example above, there are a few notable moments. First, we see an instance in which an implicit rule about the practice of avoiding mindless technology use when the couple is at home together becomes an explicit rule as the couple negotiates this expectation during the interview. Second, we see an example of intra-couple communication, and similar to past research, an opportunity for the couple to discuss a subject they reported previously not talking about with one another before this interaction in front of the interviewer (Bjørnholt \& Farstad, 2014).

Even though the couple agrees that "limiting phone use when they are at home together" is a rule they both share; they report never directly talking about why they have this expectation or the importance of it before the interview. This example of an intra-couple conversation points to another advantage of joint interviews as a method. First, it allows the interviewer to view instances of everyday talk unfold during the interview process, which as Duck et al. (1991) argue is an important part of relational maintenance. Second, the use of joint interviews enables individuals to ask their partner questions about their mediated practice, which naturally expands the amount and type of information revealed during this interaction. In other words, joint interviews are a productive setting for telling both relational and individual stories; and these shared reflections create more nuances in the data that you cannot access from other data collection methods alone (Allan, 1980; Mavhandu-Mudzusi, 2018). The design of joint interviews also provides the opportunity for couples to engage in metacommunication, which is normally a practice left out of everyday relational conversations. Knapp (1978) explains "what we are doing on the relationship level is sending a message about a message - communication about communication - which is called metacommunication" (p. 5, emphasis in original).

In another example of an intra-couple conversation that is unique to a joint interview setting, Keira and Dylan (dating and cohabitating for four years) discuss their mediated practices that make them feel more connected to one another. Dylan says "I like that you started tagging me in memes more, that means a lot to me." Keira replies laughing, "Awww, I didn't know that." Dylan reveals:

\section{It just brightens my day because it's like a shared joke, ya know, and someone thinks about you like 'hey, you'll find this funny' and I'm like that's nice that you're thinking of me and it's probably funny as well. So it's nice, I like that.}

Keira looks at Dylan smiling and says, "I'll be sure to keep doing that then." Here Dylan shares with Keira that the simple act of tagging him in memes on social media makes him happy and, in a sense, this becomes an example of a positive maintenance strategy the couple uses when they are physically distant (Dainton \& Myers, 2020).

This intra-couple dialogue not only provides the researcher with additional information about how technology adds texture to their relationship; it also gives the couple specific knowledge about how seemingly mundane activities can become an intimate routine. Again, we see Dylan share something with Keira that they previously did not discuss outside of this prompted environment. This is evident when Keira mentions that she did not know Dylan appreciated the act of sharing memes so much. Then we see Keira state that this is a practice she will continue and try to increase in the future since Dylan revealed that it makes him happy. This example not only demonstrates another act of unsaid behaviors becoming explicit through the context of the interview, but it also appears to expose how Dylan and Keira's future mediated communication may change. 


\section{The Realization}

Next, the choice to collect data through joint interviews can also lead participants to make realizations about their individual expectations surrounding technology use and their relational behaviors in a mediated environment. In other words, the interview process can shed light on the participant's own (or their relational) communication practices they previously did not consider. The realization becomes the next theme here and is different from intra-couple conversations because it shows moments where the individual directly talks to the interviewer, in the presence of their romantic partner, about how the process of the joint interview revealed new insights about their mediated communication practices. Rather than the dyad engaging in intra-couple conversations, where the participants often turned their bodies and gaze towards their partner, during the realization informants often focused their gaze back on the interviewer. Here informants directly referenced the process of metacommunication to the interviewer and commented on what is now visible about their unique communication patterns in this environment. For instance, Emma stated:

\section{It's funny to talk about this stuff. I mean I think talking to you about this has made me realize how many explicit conversations we've had about our technology. Like we actually do talk about it quite a bit, like I said with the kid thing, with TV, with driving, and with traveling, we've had a lot of explicit conversations about how we want to use our phones and all digital devices in our lives. And basically, it's like we need, we want it to be in super moderation, ya know.}

Towards the end of the interview, Emma commented on the fact that she realized how she and her husband of eight years have a lot of explicit conversations about their technology practices. Similar to other couples interviewed for this study, when I first asked the question about the existence of communication rules in their relationship my informants struggled to provide examples. Then as we continued to talk about how they use technology in their life and how these practices often change based on the context or goal for their interaction, the couple started to point out explicit and implicit rules they do have for technology's presence in their relational life. As the interviews progressed, my informants, like Emma, noted how the interview setting made them think differently about their technology habits and styles of communication.

In another example, Joy (engaged to her partner of four and a half years) explained during the interview, "I guess we don't text that much, ((turns to fiancé)) I am learning that we don't text that much." Again, this example shows that couples don't normally analyze their own or shared mediated practices, therefore, through the context of a joint interview where you have a researcher asking specific questions about the couple's digital communication, participants begin to realize things about their mediated practices that were previously invisible. When it comes to studying the place of technology in romantic relationships, joint interviews provide an opportunity for couples to think differently about their adoption of technology in their everyday lives. Allan (1980) argues that one of the most important advantages of joint interviews is that the researcher can see the interaction of the couple unfold as they create their accounts. I also add that this communication in action can provide insights that are nuanced and informative about the communication climate that surrounds the couple (a conclusion similar to Bjørnholt \& Farstad, 2014). Taylor and de Vocht (2011) write "the stories the partners tell each other reflect the way that couples make sense of their shared experiences as a couple" (p. 1578). Comparatively, I believe joint interviews also affect individuals' understanding of their habits and preferences, as well as future interactions shared 
between the couple as they reflect on the visible and hidden nature of mediated communication in their lives.

Next, I will highlight how the unique conversational space created by qualitative interviews can shed more light on what we know about a dyad's shared expectations for media use. In this final section, I seek to demonstrate why it is advantageous for future scholars who study mediated communication in romantic relationships to include both joint interviews and follow-up interviews, when they can, with the couple in their research design.

\section{Future Research: Relational Life After the Interview}

The nature of conducting joint interviews creates a space for couples to reflect on the nuances of their communication habits and behaviors. This research practice also invites the opportunity for implicit expectations to transform into an explicit rule due to the direct relational talk fostered by this environment. However, to truly understand if implicit rules brought up by each individual became an explicit rule in the dyad's relationship after the interview ends, a follow-up interview with the couple needs to be included in the research design (Morgan, 2016; Zarhin, 2018). Including a follow-up interview with the couple after the initial conversation can help researchers answer the following questions: Does the act of discussing this behavior in the context of a joint interview make this a rule the couple follows more strictly once the interview concludes? Does the interview context shift the weight assigned to any potential rule violations? In other words, if a rule moves from implicitly defined to an explicitly stated expectation for mediated practices, is the violation then held at a different standard?

If we agree with EVT scholars, when a norm violation occurs the witness tends to seek out an explanation from the violator and often imposes a judgment on the behavior (Hall et al., 2014). Simply put, expectations are violated when an individual behaves in a way that strays from the expected behavior (Afifi \& Metts, 1998). These violations can result in an unfavorable evaluation of the person who broke the rule, which could negatively impact a couple's relational satisfaction (Baxter et al., 2001; Miller-Ott et al., 2012). Thus, EVT declares that we follow specific rules in certain situations to maintain a positive status within our relationship and to mitigate potential conflict. So, if a communication rule transforms into an explicit expectation voiced by the couple during the joint interview, will the result of a violation impact how the individuals judge a violation in the future? It would be advantageous for future scholars to investigate what predicts the weight of a rule violation and how the instance of explicit metacommunication during an interview alters this outcome. In the end, follow-up interviews added to the research design could shed more light on the theoretical underpinnings of EVT when used to frame the study of mediated communication in romantic relationships.

Furthermore, future interpersonal scholars that use joint interviews as a data collection tool to investigate romantic couples' mediated communication and technology habits could answer the following questions if follow-up interviews are added into the research design. First, what kinds of conversations do couples have about their technology use after the interview ends? Second, do the rules the couple started to discuss during the interview become enacted in their everyday talk? In other words, did these behaviors become explicit rules the couple began to follow after the interview? If so, what are the ramifications on the couple's feelings of satisfaction (i.e., relational satisfaction and communication satisfaction; Miller-Ott et al., 2012)?

While joint interviews come with their own set of advantages, as I've outlined throughout this paper, there are also various disadvantages future scholars must consider as well. First, the practical aspects of data collection can become a limitation of the research study. Interviews, in general, may pose some scheduling conflicts, and joint interviews can sometimes be harder since 
you are now trying to juggle the schedule of three people (i.e., the dyad and the interviewer; Morgan, 2016). This hurdle also relates to follow-up interviews where the researcher may encounter some difficulty arranging a time to interview the couple again. Along the same lines, another challenge could emerge if one member of the dyad feels 'forced' into the interview, this can occur when there is a gatekeeper that is doing the recruitment, thus the interviewer needs to make sure that neither participant's consent is falsely constructed (Mellor et al., 2013). Specifically, the consent to participate should not be influenced by "couple relationship dynamics, a desire to please their partner, the potential difficulty of non-participation, and their partner's persuasion" (Mellor et al., 2013, p. 1404).

The second weakness of joint interviews is that the presence of the romantic partner may obstruct the production of complete accounts (Allan, 1980). In this case, individuals may be more truthful about activities, thoughts, and feelings if they are sure their significant other will not have access to that information. Therefore, it may be best in some situations to interview couples separately so you can get information about potentially sensitive issues that the couple may or may not have discussed with each other (Lowton, 2018; Mellor et al., 2013). Then conduct a joint interview on a separate occasion to take into consideration the material you would not receive with individual interviews alone.

Silencing can also be a unique constraint for this method choice due to relational dynamics like power differences in the partnership or individual personality differences and comfort levels (Gubrium \& Holstein, 2009; Mavhandu-Mudzusi, 2018; Mellor et al., 2013; Morgan, 2016). For instance, in joint interviews, there can be an "imbalance of turn-taking or domination of one partner during the interview" (Lowton, 2018, p. 139). This may prevent the researcher from giving an equal voice to both participants resulting in partial data (Zarhin, 2018). Finally, couple desirability bias may also become a limitation in the data gathered with joint interviews. Taylor and de Vocht (2011) state, in joint interviews participants, may present "answers that are perceived to be acceptable to the partner, or are consistent with the partner's perceived (or known) position" ( p. 1577). This desirability bias or the underlying cultural assumption of what a 'happy' romantic relationship should look like may create the potential for embarrassment or false information if this image is not upheld in front of the interviewer (Morgan, 2016; Taylor \& de Vocht, 2011). With any chosen method there are always challenges to consider when creating a research design and it is up to the researchers to keep these in mind as they collect and analyze data, as well as write up the final report.

The inherent limitations of qualitative interviews remind future scholars that as social scientists our main goal when studying human subjects is to ensure that the individuals we research are not harmed (physically or mentally) or treated in a way that ends up humiliating or offending them (Lowton, 2018; Zarhin, 2018). This means that at every stage of the research design process, we must be mindful of our choices to ensure that we do not inflict any harm on our participants. For instance, not all discussions during an interview with a romantic couple will be positive, if a couple gets into a fight during the interview, the researcher cannot take sides or present the data in a way that glorifies one partner over the other (Bjørnholt \& Farstad, 2014; Gubrium \& Holstein, 2009; Lowton, 2018; Taylor \& de Vocht, 2011). More than other methods, joint interviews may stir up relational tensions or arguments and the researcher must not appear to act as a relational counselor or justify one partner's behavior over the other (Lowton, 2018). Not only will this damage the rapport between the interviewer and participants, but it will also harm the researcher's credibility and professionalism. Lowton (2018) adds: 
In some cases, it may become necessary to end the interview at a point where conflict does not seem to be resolving, and allow the couple privacy. However, if the disagreement has escalated into 'full-blown' conflict the interviewer may feel that to leave the couple may increase the vulnerability or risk of harm of one of the partners. At whatever point the interview is brought to an end, the interviewer will need to check whether consent still stands for the interview up to that point and to what extent emotional harm has occurred. (p. 140)

Whenever conducting interviews, especially joint interviews, where the interviewer is a third-party observer into these unique relationship moments, the role of the researcher during this interaction must be considered. The interaction between the interviewer and interviewees creates a conversational space. How safe the respondents feel in this setting ultimately influences the stories and experiences they share (Pezalla et al., 2012). The ethical challenges, along with the larger research goals, must be considered carefully as interpersonal scholars plan how to best investigate a romantic couple's interactions with more depth and dynamism.

\section{Final Thoughts}

To review, the purpose of this paper is to present a reflexive account of how the use of joint interviews with a romantic couple produces a dynamic conversational environment for unspoken practices to be discovered. I conclude that another strength of joint interviews is the transformative power of this method to provide a space for the couple to reflect on their shared expectations for media use which can potentially alter their behavior once the questioning ends. For example, these dyadic interactions occurred in real-time during the interview when the previous talk about a specific behavior was never reported to be explicitly discussed between the couple. The observed intra-couple conversations point to another advantage of joint interviews as a method when investigating relational communication since they permit the researcher to view instances of everyday talk unfold during the interview process. Based on the goals of the original study framing this paper, I believe joint interviews can provide a more comprehensive picture of how romantic relationships exist in a contemporary age, as well as in the mediated spaces people inhabit.

As others have said before, joint interviews uncover additional information about the couple's shared experiences that individual interviews alone do not offer (Allan, 1980; Bjørnholt $\&$ Farstad, 2014; Taylor \& de Vocht, 2011). This paper reveals that joint interviews are a fruitful method to use if you want to investigate how a couple's relationship takes shape through mobile technology. The larger methodological implication of this research sheds light on the fact that joint interviews, unlike other data collection tools, creates a space for people to reflect on relational communication practices that are often invisible. As social scientists, we must acknowledge that when joint interviews become part of our research toolbox, the process of metacommunication will inevitably impact the couple's relational communication at that moment, and potentially after the interviewer removes themselves from the conversation. Of course, many factors affect what type of method a researcher should use, including the decision to interview couples together or separately. These factors involve the "quality of the relationship" and the "nature of the research topic" (Allan, 1980, p. 206). Just like the study of interpersonal relationships, qualitative research as a methodology is dynamic and fluid, and conducting joint interviews is essentially a relational practice (Polak \& Green, 2016; Torgé, 2013).

Due to the nature of joint interviews, future scholars must remember that we inevitably study the unspoken communication practices between loved ones, and our involvement in this 
process can potentially transform the dyad's shared expectations for mediated communication. Ultimately, this data collection tool can provide rare insights into how the private aspects of relationships operate when researchers explore mediated relational communication. Joint interviews can enhance the quality and depth of the data collected (Mavhandu-Mudzusi, 2018). However, since this technique can directly affect the relationship of the couple, researchers must think carefully about the outcome of joint interviews as a method of data collection when designing their study. Practices of reflexivity need to recognize the presence of the researcher during data collection (e.g., "what an interviewer says and how it is said; Pezalla et al., 2012, p. 181, emphasis in original), as well as the role of the conversational space on the couple's future encounters.

The conclusions provided in this paper are beneficial to future relational and new media scholars both domestic and international who seek to study technology use in romantic relationships. The larger implication of this work is to encourage researchers to think critically about how dyad's metacommunication around technology use in a joint interview setting provides an additional opportunity to examine digital communication and media habits inherent in relational life. As I noted earlier, the contribution this paper offers to other qualitative scholars is to encourage future researchers to acknowledge the potential effects this practice may have on the couple's future relational communication habits and expectations. Ultimately, I believe there is a significant benefit to include follow-up interviews with the couple into the larger research design as a way to further explore how mediated communication in romantic relationships transforms after the interview concludes, and as the partnership continues to develop or potentially comes to an end.

\section{References}

Afifi, W. A., \& Metts, S. (1998). Characteristics and consequences of expectation violations in close relationships. Journal of Social \& Personal Relationships, 15(3), 365-392. https://doi.org/10.1177/0265407598153004

Allan, G. (1980). A note on interviewing spouses together. Journal of Marriage \& Family, 42(1), 205-210. https://doi.org/10.2307/351948

Baxter, L. A., Dun, T., \& Sahlstein, E. (2001). Rules for relating communicated among social network members. Journal of Social \& Personal Relationships, 18(2), 173-199. https://doi.org/10.1177/0265407501182002

Baym, N. K. (2008). What constitutes quality in qualitative internet research? In N. K. Baym \& A. Markham (Eds.), Internet inquiry: Conversations about method (pp. 173-189). SAGE Publications.

Bjørnholt, M., \& Farstad, G. R. (2014). “Am I rambling?” On the advantages of interviewing couples together. Qualitative Research, 14(1), 3-19. https://doi.org/10.1177/1468794112459671

Brinkmann, S. (2018). The interview. In N. K. Denzin \& Y. S. Lincoln (Eds.), The SAGE handbook of qualitative research (5th ed., pp. 997-1038). SAGE Publications.

Burgoon, J. K. (2015). Expectancy violations theory. In C. R. Berger \& M. E. Roloff (Eds.), The international encyclopedia of interpersonal communication (pp. 1-9). John Wiley \& Sons, Inc.

Burgoon, J. K., \& Jones, S. B. (1976). Toward a theory of personal space expectations and their violations. Human Communication Research, 2(2), 131-146. https://doi.org/10.1111/j.1468-2958.1976.tb00706.x

Dainton, M., \& Myers, S. A. (2020). Mediated communication and relationships. In Communication and relationship maintenance (pp. 149-170). Cognella. 
Denzin, N. K., \& Lincoln, Y. S. (2018). Introduction: The discipline and practice of qualitative research. In N. K. Denzin \& Y. S. Lincoln (Eds.), The SAGE handbook of qualitative research (5th ed., pp. 29-71). SAGE Publications.

Duck, S., Rutt, D. J., Hurst, M. H., \& Strejc, H. (1991). Some evident truths about conversations in everyday relationships: All communications are not created equal. Human Communication Research, 18(2), 228-267. https://doi.org/10.1111/j.14682958.1991.tb00545.x

Eisikovits, Z., \& Koren, C. (2010). Approaches to and outcomes of dyadic interview analysis. Qualitative Health Research, 20(12), 1642-1655. https://doi.org/10.1177/1049732310376520

Gershon, I. (2010). The breakup 2.0: Disconnecting over new media. Cornell University Press.

Gubrium, J. F., \& Holstein, J. A. (2009). Analyzing narrative reality. SAGE Publications.

Guest, G., Namey, E., \& Chen, M. (2020). A simple method to assess and report thematic saturation in qualitative research. PLoS ONE, 15(5), 1-17. https://doi.org/10.1371/journal.pone.0232076

Hall, J. A., Baym, N. K., \& Miltner, K. M. (2014). Put down that phone and talk to me: Understanding the roles of mobile phone norm adherence and similarity in relationships. Mobile Media \& Communication, 2(2), 134-153. https://doi.org/10.1177/2050157913517684

Hermanowicz, J. C. (2013). The longitudinal qualitative interview. Qualitative Sociology, 36(2), 189-208. https://doi.org/10.1007/s11133-013-9247-7

Humphreys, L. (2018). The qualified self: Social media and the accounting of everyday life. MIT Press.

Jenner, B. M., \& Myers, K. C. (2019). Intimacy, rapport, and exceptional disclosure: A comparison of in-person and mediated interview contexts. International Journal of Social Research Methodology, 22(2), 165-177. https://doi.org/10.1080/13645579.2018.1512694

Knapp, M. L. (1978). Social intercourse: From greeting to goodbye. Allyn \& Bacon.

Lindlof, T. R., \& Taylor, B. C. (2002). Design I: Planning research projects. In T. R. Lindlof \& B. C. Taylor (Eds.), Qualitative communication research methods (3rd ed., pp. 71-96). SAGE Publications.

Lowton, K. (2018). He said, she said, we said: Ethical issues in conducting dyadic interviews. In R. Iphofen \& M. Tolich (Eds.), The SAGE handbook of qualitative research ethics (pp. 133146). SAGE Publications. https://www.doi.org/10.4135/978152643544

Mavhandu-Mudzusi, A. H. (2018). The couple interview as a method of collecting data in interpretative phenomenological analysis studies. International Journal of Qualitative Methods, 17, 1-9. https://doi.org/10.1177/1609406917750994

Mellor, R. M., Slaymaker, E., \& Cleland, J. (2013). Recognizing and overcoming challenges of couple interview research. Qualitative Health Research, 23(10), 1399-1407. https://doi.org/10.1177/1049732313506963

Miller-Ott, A. E., Kelly, L., \& Duran, R. L. (2012). The effects of cell phone usage rules on satisfaction in romantic relationships. Communication Quarterly, 60(1), 17-34. https://doi.org/10.1080/01463373.2012.642263

Morgan, D. (2016). Essentials of dyadic interviewing. Routledge.

Morse, J. M. (1995). The significance of saturation. Qualitative Health Research, 5, 147-149. https://doi.org/10.1177/104973239500500201

Neale, B. (2018). What is qualitative longitudinal research? Bloomsbury Publishing. 
Pezalla, A. E., Pettigrew, J., \& Miller-Day, M. (2012). Researching the researcher-as-instrument: An exercise in interviewer self-reflexivity. Qualitative Research, 12(2), 165-185. https://doi.org/10.1177/1468794111422107

Polak, L., \& Green, J. (2016). Using joint interviews to add analytic value. Qualitative Health Research, 26(12), 1638-1648. https://doi.org/10.1177/1049732315580103

Roggensack, K. E., \& Sillars, A. (2014). Agreement and understanding about honesty and deception rules in romantic relationships. Journal of Social and Personal Relationships, 31(2), 178-199. https://doi.org/10.1177/0265407513489914

Sanip, S. (2020). Research methodological challenges and recommendations for conducting a comparative qualitative longitudinal study across two countries on different continents. International Journal of Qualitative Methods, 19, 1-10. https://doi.org/10.1177/1609406920917493

Scissors, L. E., \& Gergle, D. (2013, February). "Back and forth, back and forth": Channel switching in romantic couple conflict. Proceedings of the 2013 Conference on Computer Supported Cooperative Work -CSCW '13. ACM Digital Library, San Antonio, TX. https://doi.org/10.1145/2441776.2441804

Shimanoff, S. B. (1980). Communication rules theory and research. SAGE Publications.

Taylor, B., \& de Vocht, H. (2011). Interviewing separately or as couples? Considerations of authenticity of method. Qualitative Health Research, 21(11), 1576-1587. https://doi.org/10.1177/1049732311415288

Torgé, C. J. (2013). Using conjoint interviews with couples that have been living with disabilities and illnesses for a long time-implications and insights. Qualitative Studies, 4(2), 100-113. https://doi.org/10.7146/qs.v4i2.8860

Zarhin, D. (2018). Conducting joint interviews with couples: Ethical and methodological challenges. Qualitative Health Research, 28(5), $844 \quad-854$. https://doi.org/10.1177/1049732317749196

\section{Notes on Contributor}

Jamie Foster Campbell, Ph.D. candidate, Department of Communication, University of Illinois at Chicago. Jamie Foster Campbell is a new media and communication scholar. Her work focuses on relational communication, mobile media, and mediatization. Specifically, her research explores how technology becomes part of our relational identity, influences our interpersonal communication, and creates a sense of shared space. Correspondence concerning this article should be addressed to Jamie Foster Campbell, Communication Studies Department, University of Illinois at Chicago, 1007 W Harrison Street, Chicago, IL 60607. Email: jfoste2@uic.edu; https://orcid.org/0000-0002-3539-8667

Manuscript received March 31, 2021

Final revision received May 13, 2021

Accepted May 14, 2021 